\title{
Application of Sliding Mode Control Technique to Regulate DC/DC Boost Converters in Systems Exploiting Photovoltaic Power Generation
}

\author{
Le Tien Phong, Ngo Duc Minh \\ Electrical Faculty, Thai Nguyen University of Technology, Thai Nguyen, Viet Nam
}

\begin{tabular}{l} 
Article Info \\
\hline Article history: \\
Received Feb 1, 2018 \\
Revised Apr 7, 2018 \\
Accepted Apr 21, 2018 \\
\hline Keyword: \\
Equivalent control signal \\
Maximum power point \\
Maximum power point tracker \\
Photovoltaic power generation \\
Sliding mode control \\
Sliding surface
\end{tabular}

Article Info

Article history:

Received Feb 1, 2018

Revised Apr 7, 2018

Keyword:

Equivalent control signal

Maximum power point tracker

Sliding mode control

\begin{abstract}
A this paper introduces a new method, called IB-SMC method, to control DC/DC boost converters in systems exploiting photovoltaic power generation. This method combines the sliding mode control technique and iterative-bisectional technique in the maximum power point tracker to change operations modes of photovoltaic power generation. The IB-SMC controller uses voltage sliding surface to evaluate the relation of instantaneous voltage at the input converter and instantaneous voltage at the maximum power point. Using information about the power of electromagnetic radiation from a pyranometer and temperature from a temperature sensor, the sliding surface and hyteresis band are changed by practically operational conditions that help improving energy efficiency of the process exploiting PVg. Simulations are carried out by Matlab/Simulink that show the ability to ensure dynamic stability by tracking instaneous maximum power point at any time whenever having any change of the operational condition, static stability by maintaining the operation point at maximum power point whenever not have any change of the operational condition and help to bring out approximately absolute energy efficiency.
\end{abstract}

Copyright @ 2018 Institute of Advanced Engineering and Science. All rights reserved.

\section{Corresponding Author:}

Le Tien Phong,

Electrical Faculty, Thai Nguyen University of Technology,

Thai Nguyen, Viet Nam.

Email: mrphonghtd1246@gmail.com

\section{INTRODUCTION}

The development of photovoltaic power generation (PVg) has helped this generation become a potential source to replace traditional sources. All studies about PVg mainly forcus on exploiting it in isolated or grid-connected systems. Like other renewable source, the main factors affecting to be able to generate power of PVg is input energy, namely: the power of electromagnetic radiation $(\mathrm{G})$, temperature of p-n junction (T) and load. Commercial productions of PVg are often verified under the standard test condition (STC) that has $\mathrm{G}=1000 \mathrm{~W} / \mathrm{m} 2$ and $\mathrm{T}=250 \mathrm{C}$. Due to the variation of input energy, the operational condition at any time is specified by a pair-value $(G, T)$ and establishes v-i and v-p characteristics. Because of the relationship between the output power and the absorbability of load, it is often exploited through power converters. Therefore, controllers play an important role in regulating control pulse to adjust a suitable load corresponding to power at the maximum power point (MPP).

A modern control technique which has been applied in systems exploiting PVg is the sliding mode control (SMC) technique. To use the SMC technique, a sliding surface must be chosen to achieve a destination. For a purpose of operating PVg at MPP, power or voltage sliding surfaces are often chosen and some researchers only used the SMC technique in controllers as a maximum power point tracker or combined the SMC technique and a technique to determine MPP in MPPT.

For the first approach, only using SMC technique, Ref [1] used the sliding surface and ref. [2] used sliding surface as power. These researches didn't correctly evaluate the essence of PVg when they considered load impedance as a constant or didn't have any solution to determine information about power at MPP to the 
derivative conditions at the peak of vpv-ipv characteristic, where vpv and ipv are output voltage an current of PVg.

For the second approach, combining the SMC technique and P\&O (perturb and observe) or ESC (extremum seeking control) technique, controllers always actively seek a new operational point due to unknown the variation of $\mathrm{G}$ and $\mathrm{T}$, therefore they still has the same characteristic of P\&O or ESC technique [3], [4], [5], [6], [7], [8], [9].

The above analysis shows that the way to control power converter needs to change to achieve the purpose of exploiting maximum available energy from PVg. In particular, the information about MPP must be accurately determined before providing as a destination to the controller. A technique proposed to determine MPP recently, called the IB (iterative and bisectional) technique, can accurately provide parameters at MPP under any operational condition by using a pyranometer (PYR) to measure G and a temperature sensor (TempS) to measure T. The IB technique helps to calculate instantaneous values of Vmpp or Pmpp at MPP which is sent to the controller to create a suitable control pulse. In this case, the controller interferes to the power circuit of power converters to drive the current operational point to the desired point (MPP)

This paper proposes a new method combining the IB technique and the SMC technique to regulate a DC/DC boost converter. Section II will introduce mathematical description of the DC/DC boost converter, the IB technique and the SMC technique. Equivalent control signal and stable analysis will be represented in in section III. Section IV will show simulation results and comments and the last section will represent some conclusions.

\section{STRUCTURAL SYSTEM AND MATHEMATICAL MODEL}

\subsection{Structural system}

The measuring centre collects the information about G from the PYR, T from the TempS, vpv and ipv from voltage and current sensor placed at the output terminals of PVg. The proposed system to exploit PVg is described in Figure 1.

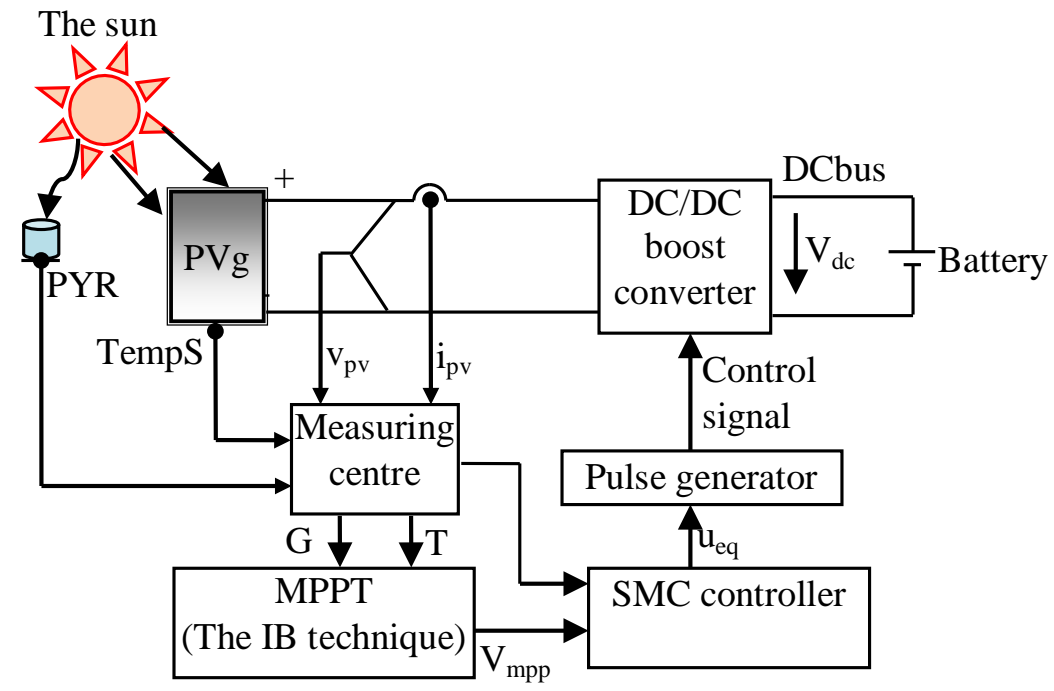

Figure 1. The proposed structure

The SMC controller calculates the equivalent control signal (ueq) which is provided to the control pulse generator to create control signal before sending to a switch placed in the DC/DC boost converter. The operational state of PVg is specified by two main parameters which is $\mathrm{G}$ and $\mathrm{T}$. In the practical operation, $\mathrm{G}$ and $\mathrm{T}$ always change continuously that make the operational point move away from real MPP. Therefore, MPPT needs to use the IB technique to accurately calculate parameters at instantaneous MPP. Value of Vmpp determined by MPPT must be provided to the SMC controller and considered as a destination for the controller under any operational condition. Combining the IB technique and the SMC technique, a new control method is constructed to regulate operational modes for PVg, called IB-SMC method. 


\subsection{Modeling the DC/DC boost converter}

Power circuit of a DC/DC boost converter is described in Figure 2a including a switch (SW) and elements $(\mathrm{L}, \mathrm{C})$ which is capable of charging or discharging energy. Equivalent circuits of this converter corresponding to on and off states of SW are depicted in Figure 2b and Figure 2c [10].

Where:

Rdc, Ldc are resistance and inductance of the inductor placed in the converter.

Cpv, Cdc are the capacitance of capacitors at the PVg side and the DCbus side.

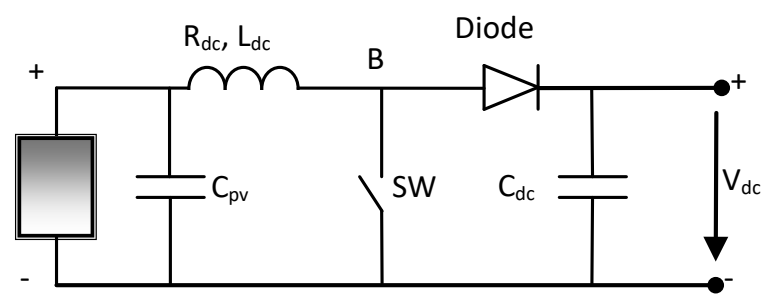

a. Power circuit

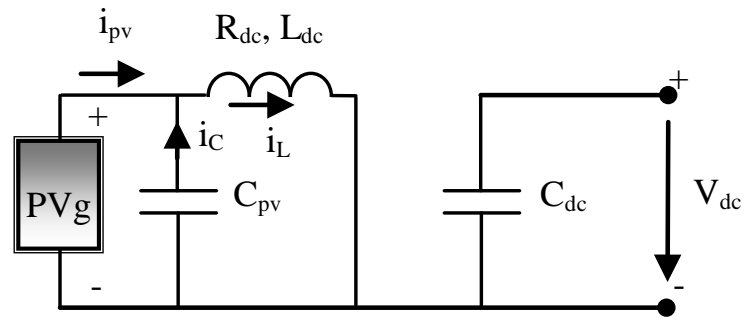

b. Equivalent circuit corresponding to SW on

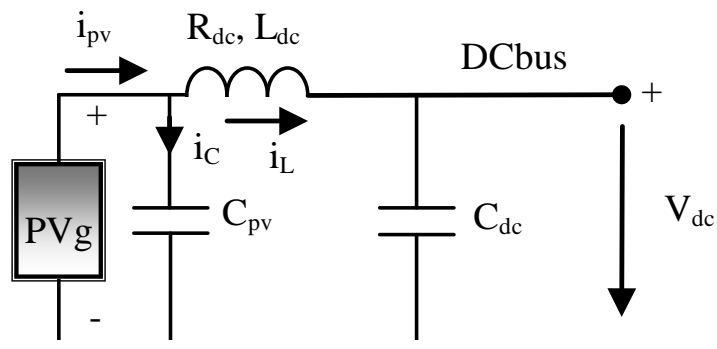

c. Equivalent circuit corresponding to SW off

Figure 2. Power circuit and equivalent circuits corresponding to on and off states of SW

Apply the Kirchhoff's first and second laws for the circuit corresponding to the on and off states of SW, we have equations (1) and (2). Tables and Figures are presented center, as shown below and cited in the manuscript.

$$
\begin{aligned}
& \mathrm{v}_{\mathrm{pv}}=\mathrm{L}_{\mathrm{dc}} \frac{\mathrm{di}_{\mathrm{L}}}{\mathrm{dt}}+(1-\mathrm{u}) \mathrm{V}_{\mathrm{dc}} \\
& \mathrm{i}_{\mathrm{pv}}=\mathrm{C}_{\mathrm{pv}} \frac{\mathrm{dv}_{\mathrm{pv}}}{\mathrm{dt}}+\mathrm{i}_{\mathrm{L}}
\end{aligned}
$$




\subsection{Modeling PVg}

Equivalent circuit of PVg is described in Figure 3 [11].

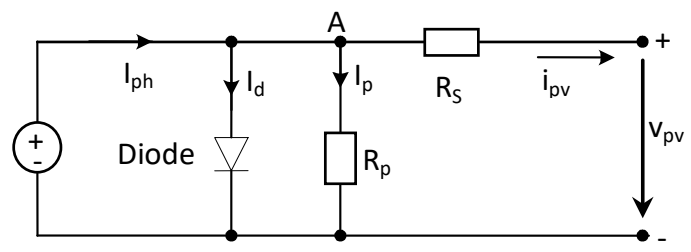

Figure 3. Equivalent circuit of PVg

The relationship between current ipv and voltage vpv at output terminals of PVg is defined by (3):

$\mathrm{i}_{\mathrm{pv}}=\mathrm{I}_{\mathrm{ph}}-\mathrm{I}_{0}\left\{\exp \left(\frac{\mathrm{v}_{\mathrm{pv}}+\mathrm{i}_{\mathrm{pv}} \mathrm{R}_{\mathrm{s}}}{\mathrm{nV} \mathrm{V}_{\mathrm{t}}}\right)-1\right\}-\frac{\mathrm{v}_{\mathrm{pv}}+\mathrm{i}_{\mathrm{pv}} \mathrm{R}_{\mathrm{s}}}{\mathrm{R}_{\mathrm{p}}}$

Output power from PVg is defined by (4):

$\mathrm{p}_{\mathrm{pv}}=\mathrm{v}_{\mathrm{pv}} \mathrm{i}_{\mathrm{pv}}$

where: RS is series resistor; Rp is parallel resistor; I0 is reserve saturation current; Iph is photo-generated current; Vt is themal voltage at $p-n$ junctions; $n$ is ideality factor.

\subsection{Description of the IB technique}

The IB technique is proposed basing on accurately mathematical model of PVg to have pair-value (Vmpp, Impp) corresponding to the peak of the $\mathrm{V}\urcorner_{\mathrm{pv}}-\mathrm{p}_{\mathrm{pv}}$ curve which is set by a value-pair (G, T). By combining the iterative technique and bisectional technique, MPPT calculates and observe power value of continuous three points to have the evaluation about the moving statement of operating points. The IB technique is represented in Figure 4.

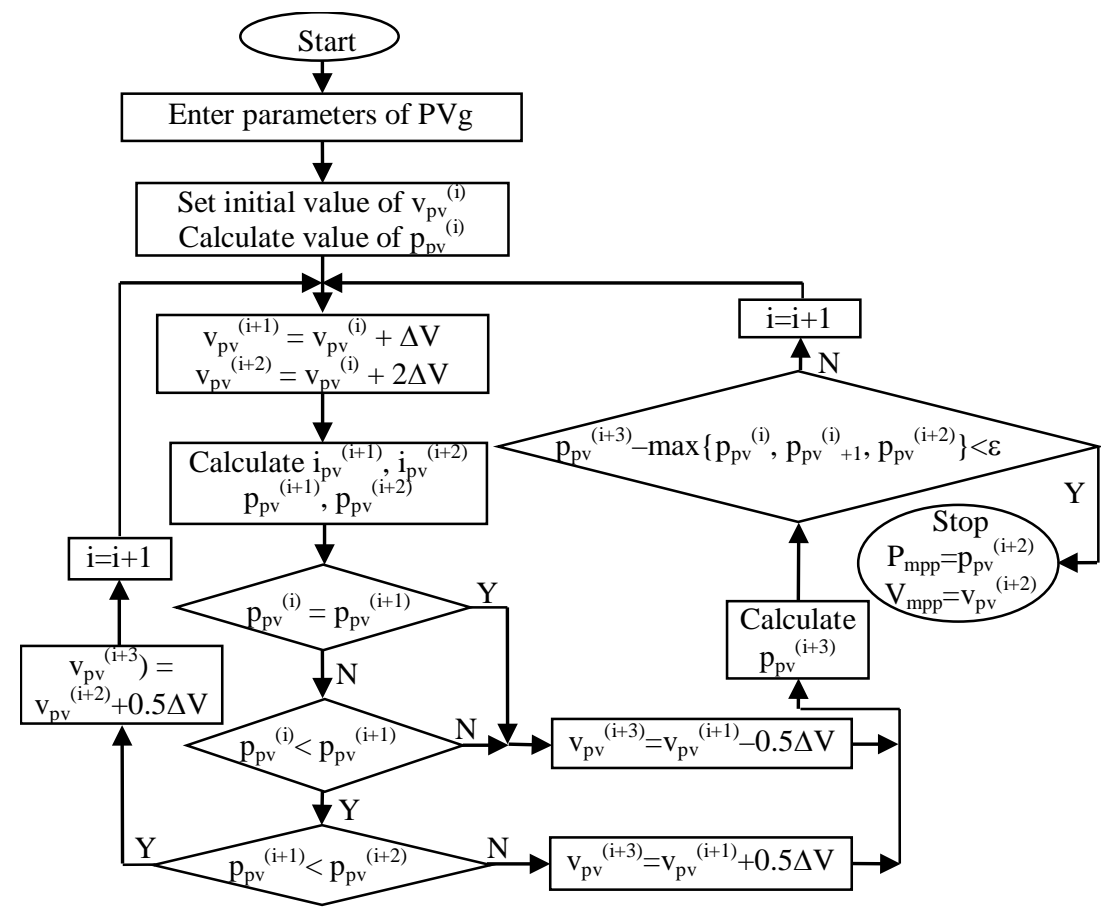

Figure 4. The IB technique to determine MPP 
3. THE IB-SMC METHOD

\subsection{State system of equations}

Rewrite (1) and (2) equations, we have the state system of equations (5):

$$
\left\{\begin{array}{l}
\mathrm{x}_{1}=\frac{\mathrm{x}_{2}-\mathrm{V}_{\mathrm{dc}}}{\mathrm{L}_{\mathrm{dc}}}+\frac{\mathrm{V}_{\mathrm{dc}}}{\mathrm{L}_{\mathrm{dc}}} \mathrm{u} \\
\cdot \mathrm{x}_{2}=\frac{\mathrm{i}_{\mathrm{pv}}-\mathrm{x}_{1}}{\mathrm{C}_{\mathrm{pv}}}
\end{array}\right.
$$

where: $\mathrm{x}=[\mathrm{x} 1 \mathrm{x} 2]=[\mathrm{iL} \mathrm{vpv}]$ is the state vector,

$$
f(x)=\left[\begin{array}{c}
\frac{x_{2}-V_{d c}}{L_{d c}} \\
\frac{i_{p v}-x_{1}}{C_{p v}}
\end{array}\right]_{\text {is drift vector, }} g(x)=\left[\begin{array}{c}
\frac{V_{d c}}{L_{d c}} \\
0
\end{array}\right]_{\text {is control vector }}
$$

\subsection{Mặt trượt}

To control DC/DC boost converter, sliding surface is defined by a function as depicted in (6) or (7):

$$
\mathrm{h}=\mathrm{K}_{\mathrm{b}}\left(\mathrm{x}_{2}-\mathrm{V}_{\mathrm{mpp}}\right)+\mathrm{K}_{\mathrm{c}} \mathrm{i}_{\mathrm{C}}=0
$$

or

$$
\mathrm{h}=\mathrm{K}_{\mathrm{b}}\left(\mathrm{x}_{2}-\mathrm{V}_{\mathrm{mpp}}\right)+\mathrm{K}_{\mathrm{c}} \mathrm{i}_{\mathrm{C}}=0
$$

where:

Vmpp is the value of voltage at MPP which must be reached (the result of the IB technique and considered as a constant at the considered time corresponding to a pair-value $(G, T)$ ), $i_{p v}$ is the function of variable $x_{2}$ $\left(\mathrm{i}_{\mathrm{pv}}=\mathrm{i}_{\mathrm{pv}}\left(\mathrm{x}_{2}\right)\right), \mathrm{Kb}$ is a real number that is specified for hysteresis band of output voltage of PVg, Kc (V/A) is the quantity which evaluates the relative sliding speed between voltage and current of Cpv. Value of Kb affects to the chattering phenomenon (vibration of vpv around Vmpp) in the SMC technique [3].

\subsection{Stable analysis}

To slide to MPP, dynamic of sliding mode is described on the Laplace domain by (6) and the following equation (8) [3]:

$$
\begin{aligned}
\mathrm{i}_{\mathrm{C}}=\mathrm{C}_{\mathrm{pv}} \frac{\mathrm{dx}_{2}}{\mathrm{dt}} & \Leftrightarrow \mathrm{sC}_{\mathrm{pv}} \mathrm{x}_{2}=-\frac{\mathrm{K}_{\mathrm{b}}}{\mathrm{K}_{\mathrm{c}}}\left(\mathrm{x}_{2}-\mathrm{V}_{\mathrm{mpp}}\right) \\
& \Leftrightarrow \frac{\mathrm{x}_{2}(\mathrm{~s})}{\mathrm{V}_{\mathrm{mpp}}(\mathrm{s})}=\frac{1}{1+\mathrm{s} \frac{\mathrm{K}_{\mathrm{c}} \mathrm{C}_{\mathrm{pv}}}{\mathrm{K}_{\mathrm{b}}}}
\end{aligned}
$$

To achieve MPP, equation (8) shows that value of Kb and Kc must have the same sign. The time derivative of the sliding surface is defined by (7) and the following equation (9):

$$
\begin{aligned}
& \frac{\mathrm{dh}}{\mathrm{dt}}=\mathrm{K}_{\mathrm{b}} \frac{\mathrm{dx}_{2}}{\mathrm{dt}}+\mathrm{K}_{\mathrm{c}} \frac{\mathrm{di}_{\mathrm{pv}}}{\mathrm{dt}}-\mathrm{K}_{\mathrm{c}} \frac{\mathrm{dx}_{1}}{\mathrm{dt}} \\
& \Leftrightarrow \dot{\mathrm{h}}=\mathrm{K}_{\mathrm{b}} \frac{\mathrm{dx}_{2}}{\mathrm{dt}}+\mathrm{K}_{\mathrm{c}} \frac{\mathrm{di}_{\mathrm{pv}}}{\mathrm{dx}_{2}} \frac{\mathrm{dx}_{2}}{\mathrm{dt}}-\mathrm{K}_{\mathrm{c}}\left(\frac{\mathrm{x}_{2}-\mathrm{V}_{\mathrm{dc}}}{\mathrm{L}_{\mathrm{dc}}}+\frac{\mathrm{V}_{\mathrm{dc}}}{\mathrm{L}_{\mathrm{dc}}} \mathrm{u}\right)
\end{aligned}
$$

According to Lyapunov's theory, (10) must be always suitable to exist stably around the sliding surface [12], [13]: 


$$
\left\{\begin{array}{l}
\left.\lim _{\mathrm{h} \rightarrow 0^{-}} \frac{\mathrm{dh}}{\mathrm{dt}}\right|_{\mathrm{u}=1}=\left.\frac{\mathrm{dh}}{\mathrm{dt}}\right|_{\mathrm{u}=1, \mathrm{~h}=0}>0 \\
\left.\lim _{\mathrm{h} \rightarrow 0^{+}} \frac{\mathrm{dh}}{\mathrm{dt}}\right|_{\mathrm{u}=0}=\left.\frac{\mathrm{dh}}{\mathrm{dt}}\right|_{\mathrm{u}=0, \mathrm{~h}=0}<0
\end{array}\right.
$$

Using (9) and (10), we have boundaries to limit the stable area in the process of sliding the current operational point to a new operational point (11):

$$
\left\{\begin{array}{l}
\mathrm{Ax}_{1}<\mathrm{Ai}_{\mathrm{pv}}-\frac{\mathrm{C}_{\mathrm{pv}}}{\mathrm{L}_{\mathrm{dc}}} \mathrm{K}_{\mathrm{c}} \mathrm{X}_{2} \\
\left(\mathrm{~K}_{\mathrm{b}}+\mathrm{K}_{\mathrm{c}} \mathrm{a}\right) \mathrm{x}_{1}>\mathrm{Ai}_{\mathrm{pv}}+\frac{\mathrm{C}_{\mathrm{pv}}}{\mathrm{L}_{\mathrm{dc}}} \mathrm{K}_{\mathrm{c}} \mathrm{V}_{\mathrm{dc}}-\frac{\mathrm{C}_{\mathrm{pv}}}{\mathrm{L}_{\mathrm{dc}}} \mathrm{K}_{\mathrm{c}} \mathrm{X}_{2}
\end{array}\right.
$$

where, $A=K_{b}+K_{c} \frac{d i_{p v}}{d x_{2}}$, Placed $X=x_{2}-V_{m p p}, Y=x_{1}-I_{m p p}$ It must be chosen $K b, K c$ to have $A \neq 0$ under any operational condition. From (11), we have equations (12) and (13) that represent lines of the stable boundary in the OXY plane:

$$
\begin{aligned}
& Y=i_{p v}-\frac{C_{p v} K_{c}}{A L_{d c}}\left(X+V_{m p p}\right) \\
& Y=i_{p v}+\frac{C_{p v} K_{c}}{A L_{d c}} V_{d c}-\frac{C_{p v} K_{c}}{A L_{d c}}\left(x_{2}+V_{m p p}\right)+I_{m p p}
\end{aligned}
$$

The stable area (shaded area) to exist the sliding mode in the OXY plane is described in Figure 5.

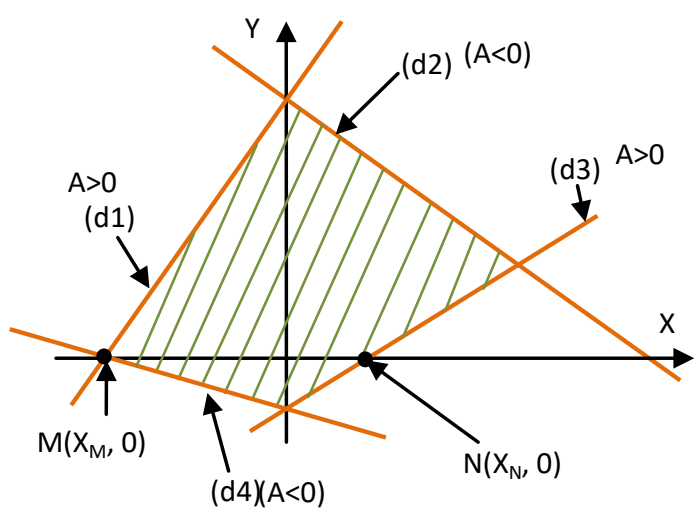

Figure 5. The stable area to exist the sliding mode in phase plane corresponding to the DC/DC boost converter

Where, lines d1, d2, d3, d4 and X-value of M and N points are defined by (14), (15), (16), (17), (18), (19):

$$
\begin{aligned}
& \mathrm{d}_{1}: \quad \mathrm{Y}=\mathrm{i}_{\mathrm{pv}}+\frac{\mathrm{C}_{\mathrm{pv}} \mathrm{K}_{\mathrm{c}}}{A L_{\mathrm{dc}}} \mathrm{V}_{\mathrm{dc}}-\frac{\mathrm{C}_{\mathrm{pv}} \mathrm{K}_{\mathrm{c}}}{A L_{\mathrm{dc}}}\left(\mathrm{x}_{2}+\mathrm{V}_{\mathrm{mpp}}\right)+\mathrm{I}_{\mathrm{mpp}} \\
& \mathrm{d}_{2}: \quad \mathrm{Y}=\mathrm{i}_{\mathrm{pv}}+\frac{\mathrm{C}_{\mathrm{pv}} \mathrm{K}_{\mathrm{c}}}{A L_{\mathrm{dc}}} V_{\mathrm{dc}}-\frac{\mathrm{C}_{\mathrm{pv}} \mathrm{K}_{\mathrm{c}}}{A L_{\mathrm{dc}}}\left(\mathrm{X}+\mathrm{V}_{\mathrm{mpp}}\right)+\mathrm{I}_{\mathrm{mpp}}
\end{aligned}
$$




$$
\begin{aligned}
& \mathrm{d}_{3}: Y=i_{\mathrm{pv}}-\frac{\mathrm{C}_{\mathrm{pv}} \mathrm{K}_{\mathrm{c}}}{A L_{\mathrm{dc}}}\left(\mathrm{X}+\mathrm{V}_{\mathrm{mpp}}\right) \\
& \mathrm{d}_{4}: \mathrm{Y}=\mathrm{i}_{\mathrm{pv}}-\frac{\mathrm{C}_{\mathrm{pv}} \mathrm{K}_{\mathrm{c}}}{A L_{\mathrm{dc}}}\left(\mathrm{X}+\mathrm{V}_{\mathrm{mpp}}\right) \\
& \mathrm{X}_{\mathrm{M}}=\frac{\mathrm{Ai}_{\mathrm{pv}} \mathrm{L}_{\mathrm{dc}}}{\mathrm{C}_{\mathrm{pv}} \mathrm{K}_{\mathrm{c}}}+\mathrm{V}_{\mathrm{dc}}+\mathrm{V}_{\mathrm{mpp}} \\
& \mathrm{X}_{\mathrm{N}}=\frac{\mathrm{Ai}_{\mathrm{pv}} \mathrm{L}_{\mathrm{dc}}}{\mathrm{C}_{\mathrm{pv}} \mathrm{K}_{\mathrm{c}}}+\mathrm{V}_{\mathrm{mpp}}
\end{aligned}
$$

Using the sliding surface and stable area, the process of moving any point to the desired point is described in Figure 6.

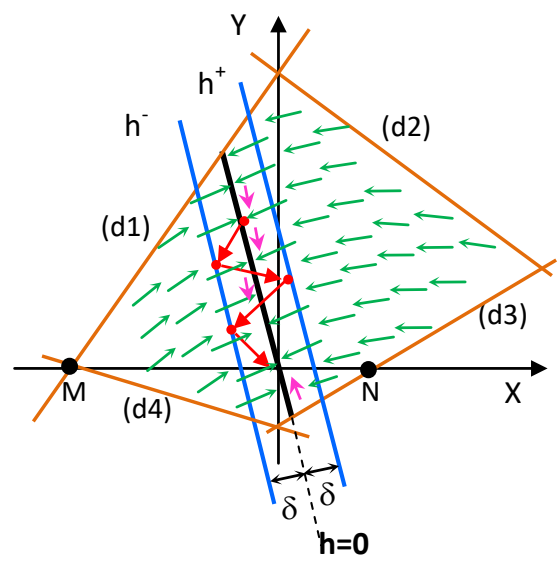

Figure 6. The process of moving operational points in the phase plane corresponding to the DC/DC boost converter

Where $2 \delta$-width of hysteresis band (area inside $\mathrm{h}+$ and $\mathrm{h}$ - boundaries) is the characteristic of the chattering phenomenon in the SMC technique when SW is on $(\mathrm{u}=1$ corresponding to the $\mathrm{h}+$ boundary or off $(\mathrm{u}=0$ corresponding to the h- boundary). Arrows represent the moving process from any original point to the desired point in co-ordinates.

\subsection{Equivalent control signal}

Equivalent control signal $\mathrm{u}_{\mathrm{eq}}$ is the equivalence between the extremely high switching frequency of the control signal $(0,1)$ and the smooth control signal. Therefore, $\mathrm{u}_{\mathrm{eq}}$ is a smooth feedback control law to maintain the orbit of ideal state that is always bounded on the surface $\mathrm{S}$ when the initial state of system $\mathrm{x}\left(\mathrm{t}_{0}\right)=\mathrm{x}_{0}$ is also on the surface $\mathrm{S}$ or $\mathrm{h}\left(\mathrm{x}_{0}\right)=0$ [12].

The derivative of function $h$ in the direction $f(x)$ is $L_{f} h=\frac{\partial h}{\partial x^{T}} f(x)$ and the derivative of function $h$ in the direction $\mathrm{g}(\mathrm{x})$ is $\mathrm{L}_{\mathrm{g}} \mathrm{h}=\frac{\partial \mathrm{h}}{\partial \mathrm{x}^{\mathrm{T}}} \mathrm{g}(\mathrm{x}) \cdot \mathrm{L}_{\mathrm{gh}}$ and $\mathrm{L}_{\mathrm{fh}}$ are defined by (20) and (21):

$$
L_{g} h=\frac{\partial h}{\partial x^{T}} g(x)=\left[\begin{array}{ll}
-K_{c} & A
\end{array}\right]\left[\begin{array}{c}
\frac{V_{d c}}{L_{d c}} \\
0
\end{array}\right] \quad \Leftrightarrow L_{g} h=-K_{c} \frac{V_{d c}}{L_{d c}}
$$




$$
\mathrm{L}_{\mathrm{f}} \mathrm{h}=\frac{\partial \mathrm{h}}{\partial \mathrm{x}^{\mathrm{T}}} \mathrm{f}(\mathrm{x})=\left[\begin{array}{ll}
-\mathrm{K}_{\mathrm{c}} & \mathrm{A}
\end{array}\right]\left[\begin{array}{c}
\frac{\mathrm{x}_{2}-\mathrm{V}_{\mathrm{dc}}}{\mathrm{L}_{\mathrm{dc}}} \\
\frac{\mathrm{i}_{\mathrm{pv}}-\mathrm{x}_{1}}{\mathrm{C}_{\mathrm{pv}}}
\end{array}\right] \Leftrightarrow \mathrm{L}_{\mathrm{f}} \mathrm{h}=-\mathrm{K}_{\mathrm{c}} \frac{\mathrm{x}_{2}-\mathrm{V}_{\mathrm{dc}}}{\mathrm{L}_{\mathrm{dc}}}+\mathrm{A} \frac{\mathrm{i}_{\mathrm{pv}}-\mathrm{x}_{1}}{\mathrm{C}_{\mathrm{dc}}}
$$

From (20) and (21), ueq $(0<$ ueq $<1)$ is defined by $(22)$ :

$$
\mathrm{u}_{\mathrm{eq}}=\frac{-\mathrm{K}_{\mathrm{c}} \frac{\mathrm{x}_{2}-\mathrm{V}_{\mathrm{dc}}}{\mathrm{L}_{\mathrm{dc}}}+\mathrm{A} \frac{\mathrm{i}_{\mathrm{pv}}-\mathrm{x}_{1}}{\mathrm{C}_{\mathrm{pv}}}}{\mathrm{K}_{\mathrm{c}} \frac{\mathrm{V}_{\mathrm{dc}}}{\mathrm{L}_{\mathrm{dc}}}} \quad \Leftrightarrow \mathrm{u}_{\mathrm{eq}}=\frac{\mathrm{V}_{\mathrm{dc}}-\mathrm{x}_{2}}{\mathrm{~V}_{\mathrm{dc}}}+\frac{A L_{\mathrm{dc}}}{\mathrm{K}_{\mathrm{c}} \mathrm{V}_{\mathrm{dc}}} \frac{\mathrm{i}_{\mathrm{pv}}-\mathrm{x}_{1}}{\mathrm{C}_{\mathrm{pv}}}
$$

\section{SIMULATION}

\subsection{Simulation parameters}

Simulation parameters of the power converter, Dcbus and switching frequency are represented in Table 1. Parameters of PVg are represented in Table 2. Function $\mathrm{n}(\mathrm{T})$ is defined by (23).

Table 1. Parameters of Power Converter, Dcbus, Switching Frequency

\begin{tabular}{lcc}
\hline & Symbol & Value \\
\hline & $\mathrm{R}(\Omega)$ & 0.5 \\
DC/DC boost converter & $\mathrm{L}(\mathrm{H})$ & $5.10^{-3}$ \\
& $\mathrm{C}(\mathrm{F})$ & $10^{-3}$ \\
Voltage at DCbus & $\mathrm{V}_{\mathrm{dc}}(\mathrm{V})$ & 12 \\
Switching frequency & $\mathrm{f}_{\mathrm{S}}(\mathrm{kHz})$ & 50 \\
\hline
\end{tabular}

$$
\mathrm{n}(\mathrm{T})=1-0.008017 \Delta \mathrm{T}+\frac{9}{400000} \Delta \mathrm{T}^{2}
$$

Where, $\Delta \mathrm{T}=\mathrm{T}-25^{0} \mathrm{C}$.

Table 2. Parameters of Pvg Under The STC

\begin{tabular}{ll}
\multicolumn{1}{c}{ Parameters } & Giá trị \\
\hline Short-circuit current $(\mathrm{A})$ & 7.36 \\
Open-circuit voltage $(\mathrm{V})$ & 30.4 \\
Voltage at MPP $(\mathrm{V})$ & 24.2 \\
Current at MPP $(\mathrm{A})$ & 6.83 \\
Current coefficiency by T $\left(\% /{ }^{0} \mathrm{C}\right)$ & 0.057 \\
Voltage coefficiency by T $\left(\% /{ }^{0} \mathrm{C}\right)$ & -0.346 \\
Power coefficiency by T $\left(\% /{ }^{0} \mathrm{C}\right)$ & -0.478 \\
Photo-generated current $(\mathrm{A})$ & 7.3616 \\
Reserve saturation current $(\mathrm{A})$ & $1.03 .10^{-7}$ \\
Thermal voltage at p-n junctions $(\mathrm{V})$ & 1.6814 \\
Series resistor $(\Omega)$ & 0.2511 \\
Parallel resistor $(\Omega)$ & 1172.1 \\
\hline
\end{tabular}

Received energy in range time ( $0 \div$ t) is defined by (24) and energy efficiency is defined by (25):

$$
\begin{aligned}
& A(t)=\int_{0}^{t} p_{p v}(t) d t \\
& H \%=\frac{A(t)}{A_{m p p}} 100 \%
\end{aligned}
$$




\subsection{Simulation results}

To evaluate the effect of $\mathrm{Kb}$ to the hysteresis band and chattering phenomenon when using the SMC technique, the energy efficiency is considered in case $\mathrm{Kb}=-0.183$ (as a constant) and in case $\mathrm{Kb}=$ $0.183^{*} \mathrm{G} / \mathrm{Gstc}$ (change by $\mathrm{G}$ ) whereas $\mathrm{Kc}=-1$ (constant). Values of $\mathrm{T}$ are given with discrete values of 250C, 350C, 450C, 550C, 650C. Simulation time is 1 s corresponding to three levels $\mathrm{G}=1000 \mathrm{~W} / \mathrm{m} 2, \mathrm{G}=600 \mathrm{~W} / \mathrm{m} 2$ and $\mathrm{G}=200 \mathrm{~W} / \mathrm{m} 2$. Simulation results are represented in Figure 7, Figure 8 and Figure 9.

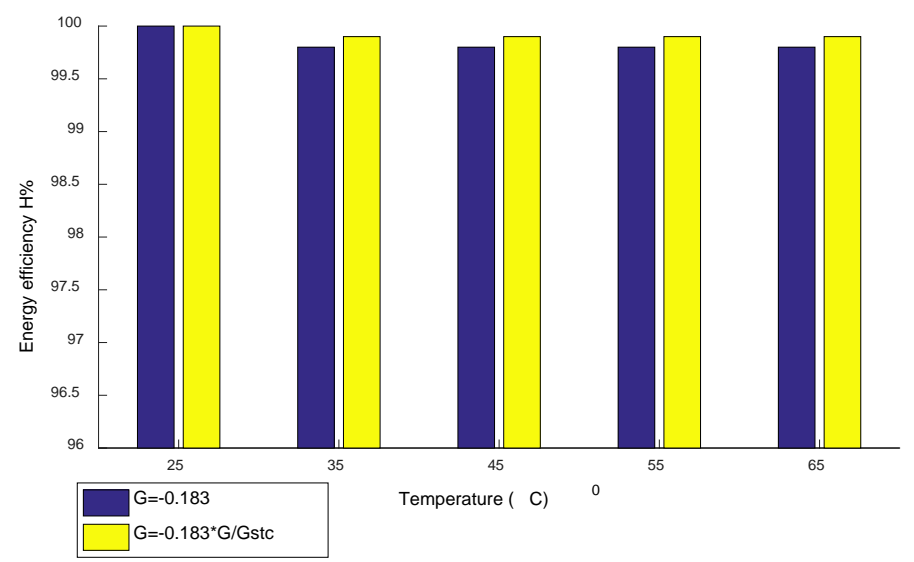

Figure 7. Energy efficiency corresponding to $\mathrm{G}=1000 \mathrm{~W} / \mathrm{m} 2$

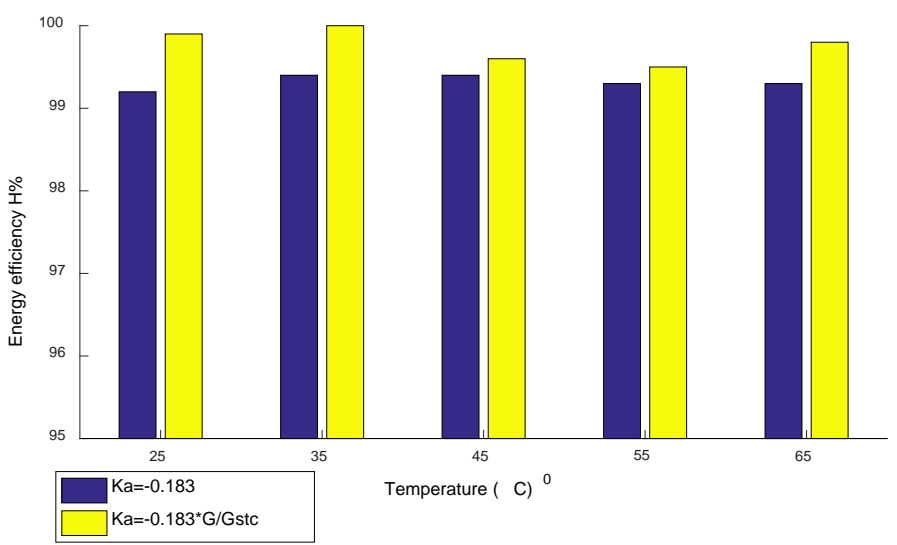

Figure 8. Energy efficiency corresponding to $\mathrm{G}=600 \mathrm{~W} / \mathrm{m}^{2}$

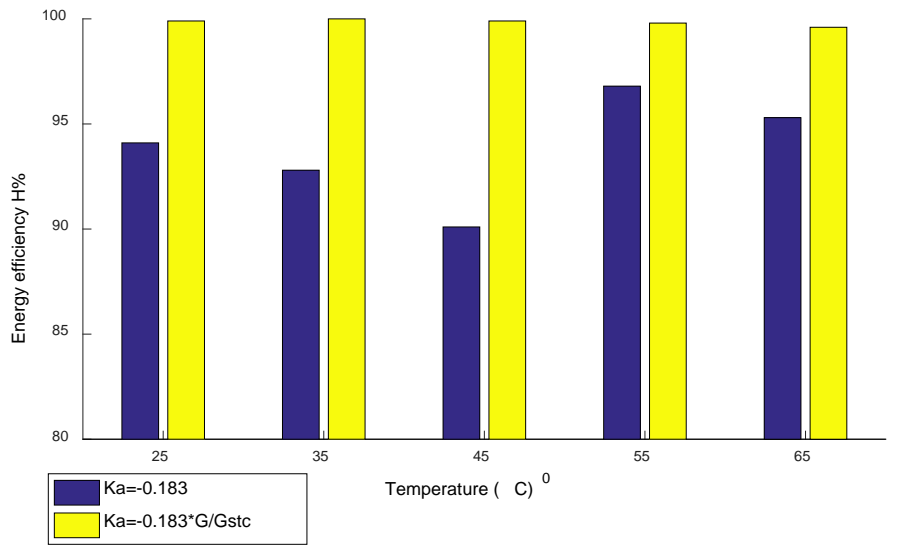

Figure 9. Energy efficiency corresponding to $G=200 \mathrm{~W} / \mathrm{m}^{2}$ 
Simulation results obtained in Figure 7, Figure 8, Figure 9 showed that the energy efficiency decreased when $\mathrm{Kb}$ didn't change whereas it always approximately achieved $100 \%$ corresponding to changing $\mathrm{Kb}$ by $\mathrm{G}$. It means that the IB-SMC method with the irradiance dependence of $\mathrm{Kb}$ can help to exploit maximum available energy from PVg due to making the hysteresis band smaller and decreasing the chattering phenomenon as described in Figure 10. Because of this, the IB-SMC method is also considered as an adaptive method under any operational condition.

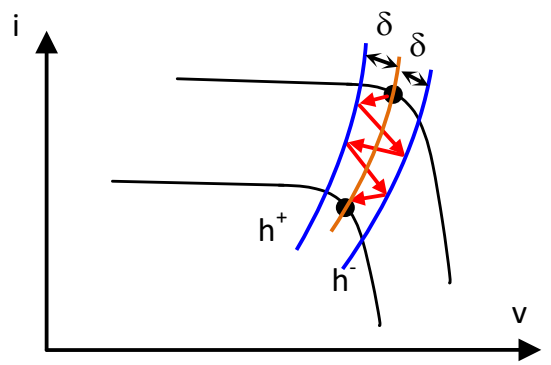

Figure 10. The movement of operational points in the v-i plane

To evaluate the ability to track MPP, a scenario to operate PVg is considered in case T=400C and the variation of $\mathrm{G}$ in 3 seconds as depicted in Figure 11.

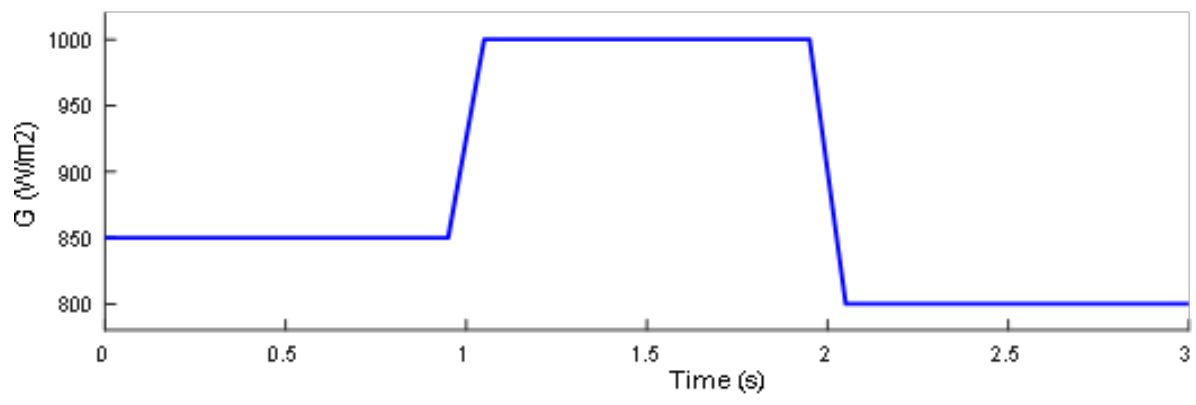

Figure 11. The variation of G

The instantaneous power characteristic about $\operatorname{ppv}(\mathrm{t}), \operatorname{Pmpp}(\mathrm{t})$ and $\mathrm{A}(\mathrm{t})$ energy characteristic in three seconds are represented in Figure 12.

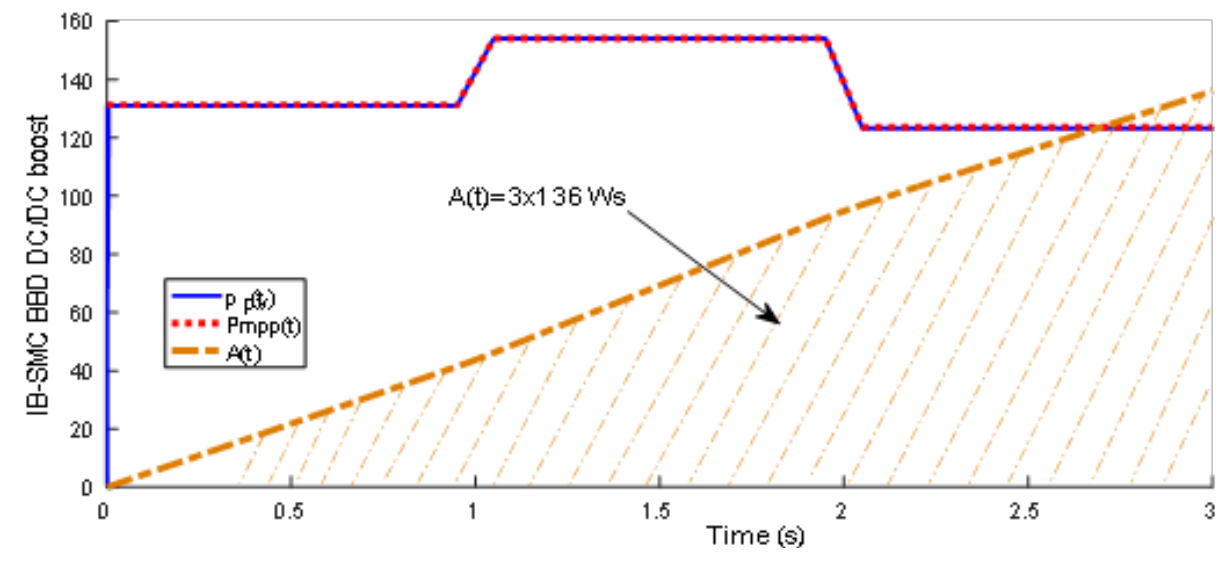

Figure 12. $\mathrm{p}_{\mathrm{pv}}, \mathrm{P}_{\mathrm{mpp}}, \mathrm{A}(\mathrm{t})$ characteristic 
Current through the Cpv capacitor is represented in Figure 13.

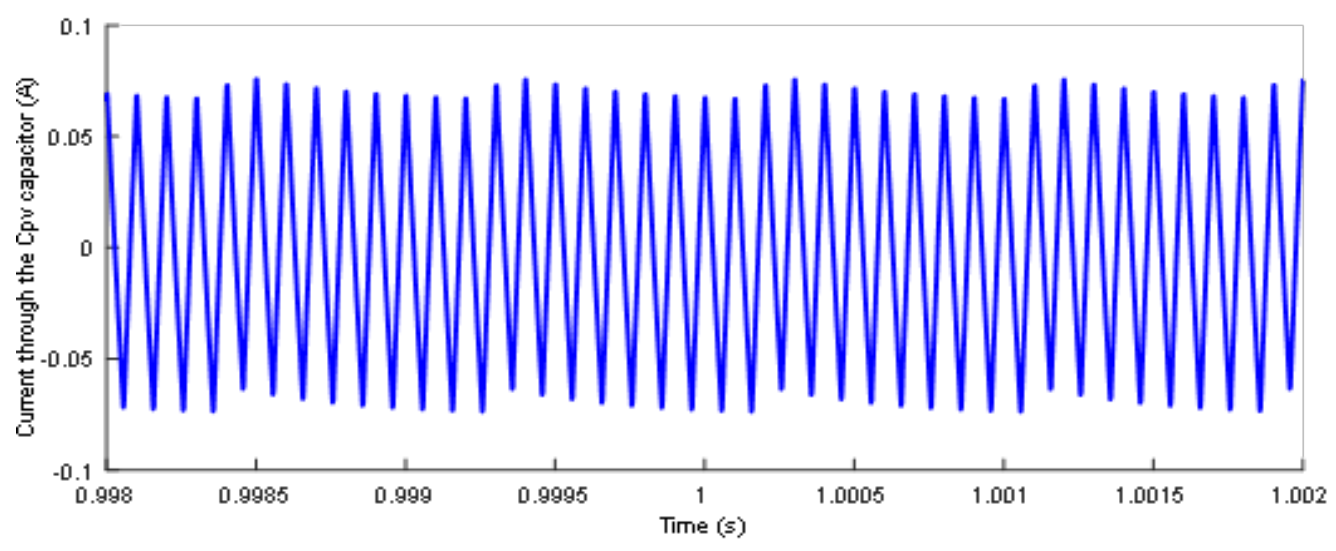

Figure 13. Current through the $\mathrm{C}_{\mathrm{pv}}$ capacitor at the $1^{\text {st }}$ second

Energy efficiency corresponding to the scenario is defined by (26):

$$
\mathrm{H} \%=\frac{3 \times 136}{408.7} 100 \%=99.83 \%
$$

Simulation results show that the $\mathrm{p}_{\mathrm{pv}}(\mathrm{t})$ characteristic always accurately tracks the $\mathrm{P}_{\mathrm{mpp}}(\mathrm{t})$ characteristic at the time of unchanging $G$ (ensure static stability) or at the time of increasing or decreasing $G$ (ensure dynamic stability) in whole process of operating PVg. Therefore, the IB-SMC method helps to almost completely exploit energy of PVg at all times.

With the simulation results of the $i_{c}$ current in Fig. 13, it has a form of a alternative current in triangular waveforms and very small amplitude. Because of having small amplitude of $i_{c}$, coefficicency $K_{c}$ in the sliding surface does not affect much to the chattering phenomenon, so it doesn't need to correct it by G.

\section{CONCLUSION}

This paper proposes a new method combing the IB technique and the SMC technique to exploit PVg. Because of using the IB technique in MPPT, the IB-SMC method becomes a effective methodology to ensure static and dynamic stability in the process of operating PVg. It also provides a different approach to exploit maximum available energy under operational condition.

To apply the SMC technique to regulate the DC/DC boost converter, parameters in the sliding surface affect much to hysteresis band, chattering phenomenon, stable ability of the system. Due to accurately describing the performance of PVg, these parameters can be determined through simulation process to evaluate prior to practical application by the survey of all operational conditions ( $G$ or $T$ varies in typical ranges).

Due to using a PYR and a TempS, instataneous information about MPP is determined and considered as a desired destination for the controller. They help to change the sliding surface and the hysteresis band according to the practically operational conditions, therefore the IB-SMC method is considered as an adaptive control method. Until now, they have many types and become more popularly because of more suitable cost. It shows the ability to apply the IB technique in practical applications. Otherwise, to measure the current through the Cpv capacitor, it needs to use small loss transformers and frequency of measuring devices must be higher several times than frequency of ic. These problems can be overcome by using high technical solutions but the cost of whole system increase very much. This makes the IB-SMC method difficult to become popular. 


\section{REFERENCES}

[1] Fan Zhang, Jon Maddy, Giuliano Premier, and Alan Guwy (2015), "Novel current sensing photovoltaic maximum power point tracking based on sliding mode control strategy”, Solar Energy, Vol. 118. (41)

[2] M. Ramesh, S. Sanjeeva Rayudu and R. Polu Raju (2015), "A New Approach to Solve Power Balancing Problem in Grid Coupled PV System using Slide Mode Control”, Indian Journal of Science and Technology, Vol 8(17), August, ISSN (Online): 0974-5645. (57)

[3] Daniel Gonz' alez Montoya, Carlos Andr’ es Ramos Paja, Roberto Giral (2015), "Improved design of sliding mode controllers based on the requirements of MPPT techniques”, IEEE Transactions on Power Electronics.

[4] Emil A. Jimenez Brea, Eduardo I. Ortiz-Rivera (2010), "Simple Photovoltaic Solar Cell Dynamic Sliding Mode Controlled Maximum Power Point Tracker for Battery Charging Applications”, Applied Power Electronics Conference and Exposition (APEC), 25th Annual IEEE. (40)

[5] Gaga Ahmed, Errahimi Fatima, ES-Sbai Jania (September 2015), "Design and Simulation of a Solar Regulator Based on DC-DC Converters Using a Robust Sliding Mode Controller”, Journal of Energy and Power Engineering, David Publishing, Vol 9. (44)

[6] Omar Boukli-Hacene (September 2013), "Robust Regulation of the Photovoltaic Voltage using Sliding Mode Control as Part of a MPPT Algorithm”, International Journal of Computer Applications, (0975 - 8887), Vol. 78, No.11. (74)

[7] Oswaldo Lopez-Santos (2015), "Contribution to the DC-AC conversion in photovoltaic systems: Module oriented converters”, Thesis for Philosophy Doctor degree, Institut National des Sciences Appliquées de Toulouse (INSA de Toulouse) in Automation. (75)

[8] Reham Haroun, Abdelali El Aroudi, Angel Cid-Pastor, Germain Garica, Carlos Olalla, and Luis Martinez-Salamero (June 2015), "Impedance Matching in Photovoltaic Systems Using Cascaded Boost Converters and Sliding-Mode Control”, IEEE Transactions on Power Electronics, Vol. 30, No. 6, June 2015. (85)

[9] Yoash Levron and Doron Shmilovitz (March 2013), "Maximum Power Point Tracking Employing Sliding Mode Control”, IEEE Transactions on Circuits and Systems, Vol. 60, No. 3. (103)

[10] Siew-Chong Tan, Yuk-Ming Lai, Chi Kong Tse (2012), “Sliding Mode Control of Switching Power Converters Techniques and Implementation”, CRC Press, Taylor and Francis Group.

[11] Lê Tiên Phong, Ngô Đức Minh, Nguyễn Văn Liễn, A New Method to Identify Maximum Power Point for Photovoltaic Generation, Hội thảo quốc tế IEEE ComManTel 2015 tổ chức tại Đà Nẵng và IEEE Xplore, ISBN: 978-1-4673-6547-5.

[12] Hebertt Sira-Ramirez, Ramon Silva-Ortigoza, "Control Design Techniques in Power Electronics Devices", Springer Publisher, e-ISBN 1-84628-459-7, 2006.

[13] Siew-Chong Tan, Yuk-Ming Lai, Chi Kong Tse (2012), "Sliding Mode Control of Switching Power Converters Techniques and Implementation”, CRC Press, Taylor and Francis Group.

\section{BIOGRAPHIES OF AUTHORS}

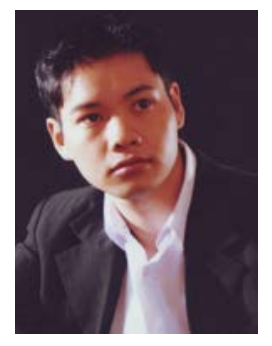

Le Tien Phong, born in 1982, received the M.Sc. degree in 2010 in Electrical Engineering from Ha Noi University of Technology and Science and working in Thai Nguyen University of Technolgy now. Interested research fields: renewable energy, control electrical energy conversions.

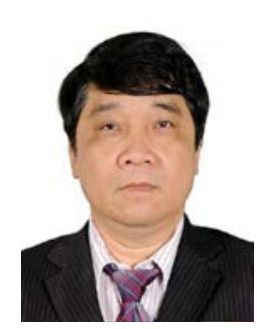

Ngo Duc Minh, received the PhD. degree in Automation from Ha Noi University of Technology and Science in 2010 and working in Thai Nguyen University of Technolgy now. His research interests include active rectifier, active filter, FACTS BESS, D-STATCOM, Control of power system, distribution grid, renewable energy in power system. 